\title{
LA RADIO EN ANDALUCÍA. FUTURO INCIERTO TRAS DÉCADAS DE CAMBIO
}

\section{Antonio $C H E C A^{*}$}

El martes 4 de octubre de 1995 todas las emisoras de radio españolas permanecieron en silencio durante un minuto. A las nueve de la mañana de dicho día la Radio quería reclamar de esa forma la atención de la sociedad española. Diez años antes se había hecho de manera similar en EE. UU. Para muchos ese silencio de la Radio era un auténtico SOS. Pero ¿cuál es el presente del medio, cuál su futuro probable? Pretendemos dar respuesta a esas dos preguntas a través del análisis del caso andaluz.

\section{PRESENCIA DE LA RADIO Y AUDIENCIAS}

A principios de 1996 el gobierno central concluyó un plan -previamente consensuado con las comunidades autónomas- para conceder 879 otras emisoras de FM en toda España. Con esa nueva tanda de concesiones se agota el espectro radioeléctrico hoy disponible, si bien queda abierta para las comunidades autónomas una puerta que posibilitará la concesión de emisoras de potencia muy baja para utilización esencialmente cultural/educativa ${ }^{1}$.

Tras ese último reparto, Andalucía queda con 166 frecuencias, muy por encima de cualquier otra comunidad, caso de Castilla y León -110- o Cataluña -96-, que son las que le siguen en número de frecuencias y, consecuentemente, de emisoras $^{2}$.

Sin embargo, Andalucía figura entre las comunidades españolas que menos tiempo dedican a sintonizar la radio, sólo un 52,3 por ciento de andaluces declaran oirla habitualmente $^{3}$. Esa baja sintonía -uno de los niveles más modestos de Europa- es especialmente acusada en el caso de la radio convencional o informativa, y está

* Profesor de la Facultad de Ciencias de la Información.

1. La introducción de la radio digital volverá a alterar a medio plazo el panorama del medio, posibilitando, entre otros aspectos, un nuevo incremento de canales y servicios.

2. Datos facilitados por el MOPTMA. Véase El País, 14-I-1996. Dado el corto ámbito de la FM, en una comunidad extensa como la andaluza varias emisoras situadas en provincias diferentes utilizan la misma frecuencia.

3. Datos referidos a 1994. EGM. 
algo atemperada en la sintonía de la radio fórmula o musical. Además, las diferencias interprovinciales son acusadas, como en tantos otros aspectos de la vida andaluza: Málaga, Almería y Cádiz figuran claramente por encima de la media estatal, pero Jaén, Córdoba y Huelva están entre las diez provincias españolas menos aficionadas a la radio. Dentro de las comunidades que tienen radio autonómica, la andaluza registra los niveles más bajos, proporcionalmente, de audiencia ${ }^{4}$.

A su vez, España es uno de los países de la UE con más baja audiencia de radio. Mientras entre daneses o alemanes más de un 80 por ciento de la población la oye habitualmente, en España sólo lo hace un 55 por ciento. Pero si el análisis se hace sobre minutos/día dedicados al medio las diferencias son aún más acusadas, un belga o un austríaco dedican el doble de tiempo que un andaluz a oir radio 5 .

Los datos aportados por las empresas que realizan encuestas sistemáticas sobre audiencia de la radio en España, el Estudio General de Medios, EGM, y el Estudio General de Audiencias, EGA, no coinciden totalmente en su análisis de la evolución reciente de la audiencia, pero permiten trazar un panorama global. Entre 1988 y 1994, siete años, la audiencia ha permanecido prácticamente estable. Sobre 32 millones de españoles mayores de 14 años, oyen habitualmente la radio en tomo a los 18,6 millones. No crece de forma apreciable la sintonía, aunque se ha superado el bache producido tras la aparición en 1990-91 de la televisión privada y el rápido aumento del tiempo dedicado a la pequeña pantalla, que en 1995 comenzó a su vez a estabilizarse.

\section{PROBLEMAS ECONÓMICOS}

Una audiencia que no crece y -segundo factor- una publicidad que tampoco aumenta. El conjunto de la radio española ingresa en los últimos años en tomo a los 50.000 millones de pesetas anuales en concepto de publicidad ${ }^{6}$. Si se divide esa cifra entre el número de emisoras -1.700 oficialmente, bastantes más de 2.200 en la práctica en 1995-, se vería que los ingresos publicitarios promedio de las

4. Durante el segundo semestre de 1995, la audiencia de Canal Sur Radio fue (según el EGA) de unas 148.000 personas, para su programa convencional, muy por bajo de Catalunya Radio -459.000 - y a nivel similar que Euskal Irratia, pero para una población, en este último caso, sólo una tercera parte de la andaluza. Según otras fuentes (Anuario de Fundesco, 1994), la audiencia de Canal Sur Radio se situaba en 1993 en torno a 200.000 personas, para el programa convencional, y 150.000 para el musical. En este caso también muy por bajo de Catalunya Radio y, proporcionalmente a la población de cada Comunidad, de la Radio Vasca. Sólo la radio autonómica madrileña presenta una audiencia proporcionalmente muy inferior a la andaluza.

5. Por contra, como es sabido, el tiempo dedicado por los españoles en general y los andaluces en concreto a la televisión es muy superior al promedio europeo. En 1995, según Sofres, cada español con al menos cinco años de edad vio de promedio 211 minutos diarios de televisión. Andalucía se sitúa muy por encima de la media del Estado.

6. 53.000 millones fue la facturación conjunta de la radio española en 1994, según el anuario “Comunicación Social/Tendencias 1995" de Fundesco. 
emisoras privadas españolas - la radio estatal y la autonómica no tienen ingresos por ese concepto- estarían en tomo a los 25 millones anuales, cifra de por si bien modesta, pero que además encubre las profundas diferencias entre una gran mayoría de emisoras que no alcanza esa cantidad y la minoría de las que la superan. Los ingresos publicitarios de la radio española -sin que la andaluza suponga excepción- son sin duda bajos, pero el porvenir, si hemos de medirlo en función de la evolución de los países vecinos, no es muy halagüeño: la publicidad en radio viene representando en España en tomo al 7 por ciento del gasto global en publicidad, porcentaje por encima del habitual en Europa y sólo similar al de Francia. En Italia o Alemania, por ejemplo, la publicidad en radio no alcanza siquiera el 4 por ciento de la inversión publicitaria en medios?.

Los datos anteriores tienen su correlato en la baja rentabilidad que en conjunto ofrece hoy el medio, muy inferior, por ejemplo, a la de la prensa diaria. En 1993 el conjunto de la radio privada perdió en España en torno a los 6.000 millones de pesetas, según declaraba a mediados de 1994 Alfonso Cavallé, presidente de la Asociación Española de Radiodifusión Comercial. Sonó la alarma. La profunda reestructuración emprendida desde ese crítico 1993 por la radio en todo el estado y que en el caso andaluz ha supuesto reducir en un tercio el número de profesionales en el medio, ha hecho disminuir el déficit global del mismo, pero no han bastado para rentabilizarlo, salvo en el caso de las grandes cadenas privadas. Onda Cero, pese a ser una cadena joven y con menos costes laborales, perdía en 1994 los 323 millones, con todo un 86 por ciento menos que en el año precedente y alcanzó por fin en 1995 la rentabilidad, con 92 modestos millones de superávit. La COPE consiguió invertir la tendencia negativa en el 94, y presentaba ya unos saneados resultados -más de 1.000 millones de beneficios, lo que la convierte en la más rentable del estado- en $1995^{\circ}$. Unión Radio mantiene su rentabilidad global y, en definitiva, el conjunto del medio comenzaba a respirar en 1995, pero a costa de una fortísima reducción de gastos laborales y de producción, que no siempre se ha conseguido sin merma de calidad. Queda al margen el problema del déficit de las emisoras municipales.

Así las cosas, sin que se atisben cambios decisivos en los próximos meses e incluso por la posibilidad, dado el creciente impacto de las televisiones locales, de algunos retrocesos, el futuro no está despejado, aunque no debe ser tan inquietante como aparecía en 1993.

No todos los aspectos, además, son negativos. Por lo pronto la radio arraiga en sectores jóvenes -más de la mitad de sus oyentes no han cumplido los 35 años- y

7. Difieren las fuentes. Infoadex estima que la inversión real en Radio supuso en 1994 el 9,9 por ciento de la inversión publicitaria en medios en España, véase el Anuario Comunicación Social 1995/Tendencias, de Fundesco, página 158. En cualquier caso muestra una clara estabilidad frente al aumento de televisión y diarios y el retroceso de la publicidad en revistas.

8. Suplemento “Comunicación" de El Mundo, 29 de marzo de 1996. 
en las clases media y alta, de forma que la clase baja o la media-baja no llega a representar siquiera un tercio del total, y la radio muestra una excelente penetración en núcleos urbanos -muy perceptible, por cierto, en Andalucía-, de forma que dos tercios de sus oyentes viven en núcleos con más de 50.000 habitantes. Los españoles sin estudios apenas suponen un 8 por ciento de los que oyen la radio, pero la sintonizan usualmente un número superior de titulados universitarios, el 12 por ciento de la audiencia. Quiere decirse que el oyente típico de radio en los noventa es una persona activa, con capacidad de compra e ideas propias, de cultura urbana. No debiera ser mal objetivo para la publicidad ${ }^{9}$.

\section{EVOLUCIÓN RECIENTE}

Repasemos la evolución reciente de la radio en Andalucía. Esa evolución ha sido intensa desde finales de los setenta tras décadas de escasos cambios. Se trata de un paisaje radiofónico іпесonocible para quien hubiese vivido la radio andaluza de los sesenta y aterrizase hoy en la comunidad. La onda media casi ha desaparecido y sólo se mantiene en algunas emisoras de las tres "viejas cadenas", RNE, SER y COPE, normalmente situadas en capitales de provincia ${ }^{10}$.

El panorama está dominado por la frecuencia modulada, que desde hace años es, y cada día de forma más acusada, la más sintonizada. Dentro de la FM un mosaico complejísimo. Desde las primeras concesiones, en 1979, bajo gobierno de UCD, han aparecido y se han extinguido cadenas enteras, como Radio 80 y Antena $3^{11}$, ésta tras haber acariciado el liderazgo en audiencia a principios de los noventa. El fenómeno de las radios municipales, más de 150 en Andalucía, es otro que se añade a ese panorama muy rico, y aun hay que contabilizar la existencia de un número muy elevado, no menos también de 150 emisoras en la comunidad, de radios más o menos clandestinas o ilegales, sin olvidar el peculiar fenómeno de la presencia de emisoras en ámbitos históricamente vedados a ellas, como las cárceles (Onda Escape, Córdoba; Canal 376, Málaga), y la creciente radio escolar, con algunos ejemplos muy dignos de elogio, como Onda Lironda, en Málaga. En suma, Andalucía contabiliza en 1996 muy por encima de las 500 emisoras.

Sin duda, un panorama excesivamente poblado de antenas para la parva cosecha publicitaria. ¿Habría que invertir el proceso e ir hacia la concentración? ¿Se va de hecho a ella?.

9. Uno de los problemas de la publicidad radiofónica es la modestia de las tarifas publicitarias, que además raramente se cumplen. En 1996 el precio de una cuña de 15 segundos en una emisora de radio sevillana o malagueña oscila entre las $8.500 / 10.000$ pesetas en los programas matinales en cadena de más audiencia y las $1.200 / 1.500$ en horas menos solicitadas.

10. Los expertos, sin embargo, no consideran necesariamente en "vía muerta" la OM. En 1996 la cadena Radiolé ha iniciado su presencia en OM con una emisora en el Campo de Gibraltar. 
Por lo pronto, se ha producido en los ochenta la escisión entre radio convencional, variada e informativa, y radio fórmula, monográfica y normalmente musical. Esta tiene costes más bajos y ha conseguido sectores relevantes de audiencia, que en el caso de Andalucía representa ya por encima del 42 por ciento de los oyentes de la radio, porcentaje en continuo crecimiento. Andalucía dispone hoy de más de 80 emisoras todo música, sin contar los canales de RNE - Radio 2 y Radio 3- dedicados a música y el de Canal Sur -Canal Sur Uno-y, desde luego, sin contabilizar la amplia dedicación a la música de la mayoría de las emisoras municipales. Una joven cadena de radio fórmula, Radiolé, del grupo Unión Radio, dedicada a música española, esencialmente copla, mantiene doce de sus emisoras -número que se ha doblado en dos años- en Andalucía ${ }^{12}$. De forma significativa el resto -cuatro emisoras- está situado en Madrid y en comunidades aledañas de la andaluza: Extremadura, La Mancha y Murcia.

Junto a la aparición pujante de la radio fórmula, otro elemento destacado del proceso seguido por la radio en Andalucía es la aparición y rápida extinción de una radio independiente, considerando como tal la no dependiente de cadenas estatales ni de municipios o instituciones oficiales. Por el contrario, dominan las emisoras que, surgidas como independientes, han acabado siendo adquiridas por una u otra cadena de radio. La evolución de muchas de las emisoras concedidas por la Junta de Andalucía en 1989, es un buen ejemplo ${ }^{13}$. Ello ha supuesto la definitiva imposición -por imperativos económicos, aunque no en exclusiva por ellosdel modelo de emisora en cadena. A principios de 1996, Radio América, de Sevilla, creada tras la oleada de concesiones de la Junta de Andalucía en 1989, era traspasada por su propietario, Jesús Quintero, a la incipiente cadena estatal Radio Voz, auspiciada por el diario líder en el ámbito gallego, "La Voz de Galicia", y hasta esa fecha sin presencia en Andalucía. Radio América, pese al prestigio de su director-propietario, que intentó una programación poco convencional, había acumulado un importante déficit. La operación suponía el fin de un intento de radio ambiciosa y no dependiente de cadenas o intereses estatales, aunque la cadena Radio Voz afirma su deseo de mantener una programación propia -en torno a las diez

11. Radio 80 tuvo tres emisoras en Andalucía, en Granada, Málaga y Sevilla. Antena 3 fue incrementando su presencia en la comunidad a lo largo de los años ochenta y bordeaba la veintena de emisoras en el momento de su absorción por Unión Radio.

12. La audiencia de esta cadena fue en su primer año, 1993, de 203.000 personas y ascendió en 1995 a 320.000 (EGM). La audiencia andaluza supone el 80 por ciento de la total.

13. Algunas empresas periodísticas andaluzas se interesaron en los años 80 por el mundo de la radio y llegaron a disponer, vía concesión, de emisoras, caso muy destacado de la empresa editora del "Diario de Cádiz". Las dificultades para rentabilizarlas fue enfriando el interés del mundo periodístico por la radio y poco a poco esas emisoras fueron cambiando de propiedad y vinculándose de una u otra forma a cadenas. A principios de 1996 lo hacía Radio Valverde, propiedad del diario "Huelva Información", que se integraba en la cadena COPE. Las emisoras del grupo "Diario de Cadiz", vinculadas inicialmente a Antena 3, pasaron luego al grupo de Unión Radio, a través de la sociedad Inversiones Radiofónicas Río San Pedro, propietario de siete estaciones. 
horas- muy por encima de la usual en la radio andaluza de hoy. El 1 de febrer iniciaba sus emisiones "Radio Voz Sevilla". Por su parte, a primeros de 19961 . emisora sevillana de la Cadena Ibérica, hasta entonces sin producción propia, ini ciaba programación local.

La evolución de la radio pública es el tercer factor de cambio en la radio anda luza reciente. La paulatina reorganización y simplificación de la radio estatal, co1 la desaparición de cadenas, la última de ellas, ya a finales de los ochenta Radiocadena, se ha visto compensada por la aparición de una radio autonómica Canal Sur Radio ${ }^{14}$. La audiencia de RNE -programa convencional- representab; en 1994 en tomo al 7,5 por ciento de la obtenida por las grandes cadenas estatale en Andalucía ${ }^{15}$.

A esa radio pública estatal y regional se une la formidable presencia, siquier: a escala cuantitativa, de emisoras dependientes de ayuntamientos, de forma que : la altura de 1996 raros son los municipios andaluces con más de 10.000 habitan tes, que carecen de estación de radio y se da la circunstancia de existir inclusc emisoras en localidades, como Turrillas, en Almería, con menos de 1.000 morado res $^{16}$. Emisoras que, al contrario de las de mayor nivel, admiten publicidad par: aminorar las, con todo, imprescindibles subvenciones de los ayuntamientos. Esta: emisoras municipales vienen desarrollando en los últimos años un sugestivo perc difícil proceso de acercamiento y colaboración cara a reducir gastos, captar publi cidad y mejorar audiencias ${ }^{17}$.

\section{PROPIEDAD Y CENTRALISMO}

La evolución de la propiedad de la radio en Andalucía en las dos últimas déca. das es muy significativa. En el año 1979, bajo gobiemo de UCD, se concedieror

14. Sin ingresos publicitarios, Canal Sur Radio se nutre de las ayudas del gobierno andaluz. Un curios، informe procedente del propio Ente referido a 1993 subrayaba que la ayuda oficial por habitante ascendió : 810 pesetas en ese año, la más baja entre las radios autonómicas, que recibían entre 4.990 por habitante li vasca, la más onerosa, o 1.993 la valenciana, la de menor déficit relativo. Según el informe "El sector públicc empresarial de la comunidad autónoma de Andalucía" (Consejería de Economía y Hacienda, Sevilla, 1995) con datos referidos a 1993, a final de ese año Canal Sur Radio tenía 263 trabajadores, de ellos 15 directivos 136 fijos y 112 interinos, temporales o con contrato por obra.

15. El conjunto de la radio pública -Radio Nacional, Radiocadena- representaba en 1975 el 44 por cientc de la audiencia del medio en España. En 1990 había bajado al 19 y ha seguido perdiendo audiencia -aunqu a ritmo menor- en los últimos años, según los datos del European Institute for the Median. En febrero ds 1996 una encuesta interna entre los trabajadores de RNE realizada por el comité de empresa revelaba qu، una mayoría de ellos achacaba a la falta de independencia el descenso de oyentes.

16. Algún estudio -véase el Anuario Comunicación Social 1995/Tendencias, de Fundesco- afirna quє son 190 las emisoras municipales en funcionamiento en Andalucía en 1995. En cualquier caso, Andalucí́ es, tras Canarias y Murcia, la comunidad con más emisoras en relación con su número de municipios, cas una por cada cuatro ayuntamientos.

17. La asociación "Emisoras Municipales de Andalucía", EMA, agrupaba a finales de 1994 a 72 emisoras 
las primeras licencias de emisoras de FM. Fueron en esa ocasión 40, 32 de las cuales situadas en capitales de provincia. De ellas 16 se otorgaron a cadenas ya establecidas y las 24 restantes se repartieron entre distintas personas físicas y jurídicas, incluido un ayuntamiento -Pozoblanco-. En pocos meses la casi totalidad de las emisoras concedidas a particulares pasaron a control, de una u otra forma, de las cadenas: SER, COPE, Rueda Rato y las nuevas cadenas Antena 3 y Radio $80^{18}$.

Como el Estatuto de Autonomía establece la plena competencia de la Comunidad sobre Radiodifusión, las siguientes concesiones de licencias fueron realizadas por la Junta de Andalucía. En 1983 se otorgan licencias a 37 nuevas emisoras, de las que sólo 12 recaen en cadenas. Diez años después las cadenas han pasado a controlar 32 de esas emisoras, sólo cuatro se mantienen con sus primitivos dueños -incluido algún ayuntamiento como Lebrija- y una licencia ha sido cancelada. Finalmente, en 1989 la tanda de concesiones fue más voluminosa, 66 nuevas emisoras, casi todas ubicadas en cabeceras comarcales y otras localidades no capitales de provincia. De esas únicamente 16 se adjudicaron en principio a cadenas, lo que levantó hondo malestar en ellas. Un lustro después, de las 50 emisoras adjudicadas a otras personas o sociedades las cadenas han pasado a controlar 42 , y han sido revocadas 3 concesiones. El número de emisoras legales teóricamente independientes era a finales de 1995 de apenas cinco, de ellas varias -Radio Valverde Información, Radio América...- se han integrado en 1996 en cadenas. Si el espíritu de la ley era contrarrestar la tendencia a la concentración de la propiedad en el medio radio, la realidad ha ido por caminos bien diferentes.

Llama la atención paralelamente la tolerancia de la Administración autónoma con las emisoras clandestinas, que fuentes de la propia Junta de Andalucía evaluaban en marzo de 1995 en no menos de $152^{19}$. Aunque según un informe oficial de esas 152 emisoras "piratas" 116 tenían trámite previo a requerimiento de cierre, 23 tenían cierre notificado y aviso de sanción y las 13 restantes expediente sancionador abierto, lo cierto es que desde que el gobiemo andaluz asumiera plenas competencias sobre el medio no se ha cerrado en la comunidad ninguna emisora clandestina ${ }^{20}$. El

En octubre de ese año inició la emisión de un programa conjunto a través del satélite Hispasat, de dos horas de duración, aunque distribuido a lo largo del día en espacios de 15 o 30 minutos. Para el proyecto la EMA recibió el apoyo de la Federación Andaluza de Municipios y Provincias, FAMP. Un estudio de la firma "Panel Sur" situaba en 600.000 los oyentes andaluces de estas emisoras, pero parece una cifra muy por encima de la real. Con independencia del papel social y de contribución a la comunicación local que desempeñan, las emisoras municipales son, con escasas excepciones, dependientes financiera e informativamente de los poderes locales, con una casuística amplísima raramente ejemplar. El caso de la emisora municipal de La Carolina, donde los concejales de la oposición -del PSOE- organizaron a finales de 1995 un eneierro para protestar de que se les negase ai acceso a ella, puede ser paradigmático.

18. Estos datos y los de los siguientes párrafos proceden del volumen "Jomadas de las Administraciones Públicas sobre Radio", Generalitat, Valencia, 1995, páginas 206 a 209.

19. Véase "El Correo de Andalucía" de 27 de marzo de 1995, página 3.

20. Las plenas competencias no se hacen efectivas hasta el decreto $246 / 91$, pero especialmente desde una sentencia de 1993 del Tribunal Constitucional a instancias de la Generalitat de Catalunya. 
calificativo además de clandestina no parece apropiado. El caso bien conocido de Radio Universal, que emite en Sevilla desde la Avenida República Argentina, sede de varias consejerías de la Junta, puede ser un buen ejemplo. Incluso se han producido legalizaciones a posteriori. Un buen ejemplo puede ser el de Onda Medina, que comenzó a emitir en Medina Sidonia en julio de 1992, auspiciada por un grupo de jóvenes de la localidad y en modestos locales propios; posteriormente los promotores consiguieron unas dependencias dentro de la Casa de la Juventud, propiedad del Ayuntamiento. La orden de cierre remitida por la Junta en junio de 1993 se transformaba un año después en concesión al citado ayuntamiento gaditano de autorización para una emisora de FM que emite desde entonces en la frecuencia 107.2 -Onda Medina lo hacía en la 107.2-, compartida con radio La Isla, de San Fernan$\mathrm{do}^{21}$. Otro caso representativo es el de Radio Bellavista, creada en el barrio sevillano del mismo nombre en el verano de 1995 y con cinco kilómetros de alcance. La crea una asociación orientada a la rehabilitación de jóvenes toxicómanos, y aparece con dos horas diarias de emisión. De inmediato inicia los trámites para conseguir la legalización, la licencia, y ampliar las horas de emisión.

Al margen de los procesos en torno a la propiedad, el rasgo básico de la radio en Andalucía es hoy, pese a las apariencias, la de una paulatina sumisión a los esquemas centralizadores. Las emisoras pertenecientes a cadenas han ido reduciendo paulatinamente la programación propia, que difícilmente supera el 25 por ciento de la total y que de promedio puede situarse en tomo al 15 , con reducidas franjas horarias, matinal, mediodía y tarde-noche, con informativos y espacios locales. Las dificultades económicas del medio han obligado por otro lado a esa ya aludida reducción paulatina de plantillas con claras connotaciones descapitalizadoras ${ }^{22}$. Jubilaciones anticipadas para profesionales que han conocido etapas muy diferentes de la Radio y tienen mejor nivel salarial, generalización de contratos temporales para nuevos profesionales salidos de las facultades o -en el caso de las radios municipales- promocionados por partidos políticos, dedicados a realizar unas tareas profesionales reducidas -salvo en ciudades grandes- y burocratizadas o a "pinchadiscos" en las emisoras de radio fórmula necesitadas de voces juveniles. El resultado ha supuesto una inevitable pérdida de autenticidad y personalidad pero

21. Problema, el de las emisoras "clandestinas", pero perfectamente localizadas, que no resulta exclusivo de la comunidad andaluza. Murcia, por ejemplo, tenía a finales de 1994 unas 17 emisoras no autorizadas en pleno y bien conocido funcionamiento. Llama la atención que en una localidad turística, Aguilas, coexistan nađa menos que cuatro de estas emisoras, además de dos legales. Veáse Montoro Fraguas, Antonio, "Estructura de los medios de conunicación en la comunidad de Murcia", Anales de Historia contemporánea, $\mathrm{n}^{2} 12$, Universidad de Murcia. 1996.

22. Véase Checa, Antonio, "La financiación de la comunicación local. El caso de la Radio", en "Jomadas sobre la televisión local”. Universidad Iberoamericana de La Rábida, 1995 (en prensa). La reducción de empleo a gran escala en el medio Radio se produjo sobre todo en el bienio 1993-1994, coincidiendo con la recesión económica y el consiguiente bache publicitario, y afectó incluso a cadenas jóvenes como Canal Sur, que en el otoño de 1993 redujo actividad y desmanteló algunos centros de producción, como los de Córdoba y Jerez. 
también de experiencia y solidez profesional en buena parte de las emisoras andaluzas, que han rejuvenecido, las más veteranas, sus cuadros, pero que actuan cada día más como poste repetidor de la emisora central en Madrid, y ello vale incluso para la publicidad ${ }^{23}$.

¿Qué hay de andaluz en la programación de las emisoras andaluzas? ¿Qué pide el oyente? La experiencia del programa "Vamos Juntos", conducido por la tonadillera María del Monte en las temporadas 1993-94 y 1994-95 puede ser un baremo. A su llegada, la audiencia matutina de Canal Sur Radio estaba bajo mínimos, con alrededor de los 30.000 oyentes en las horas más duras de competencia de "Protagonistas" u "Hoy por hoy", de las estrellas de la mañana radiofónica estatal Luis del Olmo e Iñaki Gabilondo. Al final de la primera temporada la audiencia había subido a 138.000 oyentes, en un 60 por ciento mujeres, y con una hora -de 11 a 12 de la mañana- con liderazgo en la audiencia en la comunidad andaluza. Su fórmula populista, ya ensayada en los primeros años de la cadena autonómica con Carmen Abenza, mostraba la existencia de un público para esa radio, existencia confirmada, a más nivel profesional, en la temporada 1995-1996 por el programa conducido por Carlos Herrera en la misma franja horaria. Sin embargo, fuera del caso de Canal Sur Radio, los programas ofertados para toda la comunidad se reducen a esos informativos cortos -matinal, de mediodía y de tarde-noche- de las grandes cadenas, escasean programas regionales con otros contenidos y domina la radio puramente local ${ }^{24}$.

Todo ello explica también que la capacidad crítica de la radio andaluza se refugie en las tertulias, mucho más que en la información a través de los géneros radiofónicos clásicos -entrevista, reportaje, crónica...- y que aquellas sean en su gran mayoría de ámbito estatal, que resulten escasas Ias de ámbito menor y que lo específico andaluz tenga, salvo excepciones y éstas esporádicas, baja presencia en las ondas ${ }^{25}$. Es cierto que manifestaciones como el flamenco y algunos aspectos

23. La necesidad de captar publicidad y la intensa competencia ha llevado a una rebaja sustancial de las tarifas publicitarias y al incumplimiento generalizado de las mismas y además a la aceptación de una publicidad de dudosa ética que no puede acceder a la TV y rehuye los diarios. El caso de la campaña del “agua imantada" lanzada por una empresa jerezana en el bienio 1993-1994 puede ser paradigmático, pues la campaña se mantuvo un tiempo en emisoras andaluzas incluso después de que Sanidad hubiese advertido de la carencia de virtudes terapéuticas en dicha agua. Otro vicio del sistema es la proliferación de publicidad no ya encubierta sino nítida e insistente, entreverada en los programas, realizada por los mismos locutores de múltiples formas y generadora de una inevitable confusión, que provoca hastío en el oyente. Un acercamiento al problema en Catalán, Miguel, "Camuflaje publicitario en la espesura de las ondas", Comunicación y Estudios Universitarios nำ 5, CEU San Pablo, Valencia, 1995.

24. Según el Estudio General de Medios, que adjudica a Canal Sur en 1995 los 235.000 oyentes en su programación convencional, la franja horaria de mayor audiencia de la radio autonómica se sitúa precisamente entre las diez y las doce de la mañana. En 1993, según el informe de la Consejería de Economía y Hacienda ya aludido, Canal Sur Radio tuvo 7.947 horas de programación en cadena y sólo 812 de programación local -es decir, poco más de dos diarias-. Dentro de la programación en cadena la programación general ocupaba el 85 por ciento y la información deportiva el 15 restante.

25. Queda fuera del ámbito de este estudio el análisis de la degradación lingüística del medio y otros 
de la cultura popular -camavales, por ejemplo- encuentran buena acogida en $\epsilon$ medio radiofónico, pero se diluyen en el seno de una programación dominada pc la superficialidad ${ }^{26}$.

\section{CONCLUSIONES}

En suma, la radio se encuentra hoy en una peculiar encrucijada en Andalucíc La libertad de expresión aportada por la democracia y la multiplicación del núme ro de emisoras posibilitada por la revolución tecnológica de las FM no ha traido e pluralismo exigible a la nueva situación. Se mantienen dependencias de fondo, sobr una aparente emancipación. Preocupa la baja rentabilidad del medio, sin trazas d cambio substancial y que ha incidido directamente en la pérdida de calidad de tanta programaciones. La radio digital, que se anuncia como una nueva revolución ${ }^{27}$, debı contribuir a profundizar en lo que viene siendo rasgo básico del medio y que $h$ : contribuido decisivamente a mantener la audiencia pese al aumento de la oferta : el consumo televisivos: la comunicación fácil e inmediata con sus oyentes. Perı conviene no hacerse excesivas ilusiones sobre las novedades tecnológicas que si suceden atropelladamente en el mundo de la información. La radio en Andalucíi es hoy, tras dos décadas de democracia, un medio que no utiliza sus posibilidade: de influencia social y se ve manejado por algunos sectores con clara intencionalidar política.

Tras dos décadas de cambio intenso, pero proceso de ninguna forma concluido la radio andaluza -una comunidad donde son muchas las estaciones deficitariasha aprendido que no hay rentabilidad posible al margen de una cadena de ámbitc estatal $^{28}$, y que la libertad de expresión y el alto número de emisoras existentes nc

factores de empobrecimiento cultural merecedores de estudio minucioso, como la práctica desaparición di la literaria del mundo radiofónico. Véase a este respecto Checa, Antonio, "Literatura y Radio, ¿un divorcic irreversible?", Simposio Internacional sobre Literatura y Periodismo, Fundación Luis Goytisolo, El Puertı de Santa María, 1995 (en prensa).

26. El repunte de la publicidad local en 1995-1996 ha favorecido la recuperación de algunos programa: locales, pero la dimensión regional, comunitaria, de la radio, sigue siendo la gran sacrificada en la orientaciór presente de la radio andaluza.

27. Una sucinta periodización de la historia de la radio incluiría diversas etapas marcadas por destacada: innovaciones. La revolución del transistor -radio individualizada y barata- a principios de los sesenta, cuands comienza a ser dura la competencia de la televisión, rompe con la etapa inicial o clásica del medio; la de la frecuencia modulada, cronológicamente paralela a la desestatalización del medio en Europa, modific: radicalmente la audiencia desde finales de los setenta y una nueva, la radio digital, parece dibujarse en e horizonte.

28. Entre las emisoras que se han mantenido con más dignidad al margen de cadenas, suele citarse e. ejemplo de Radio Utrera -'La voz de la campiña"- surgida a principios de los años ochenta. Pero se tratz una vez más de la excepción y no de la regla. De la dificultad de mantener una programación propia en e seno de una cadena estatal es, a sensu contrario, buen ejemplo el caso de Radio Triana, integrada en Ondz Cero y paulatinamente despersonalizada hasta cesar -en 1995- de ofrecer un perfil propio. 
significan por si solas ni el avance profesional ni el aumento de la audiencia. La radio, aunque mantiene un estimable nivel de credibilidad, muy superior al de la televisión, está lejos de tener hoy el protagonismo del periodo de la transición, que culminaba con la histórica "noche de los transistores" -23 de febrero de 1981-. Es un medio por ello con rumbo incierto, pero que tendrá futuro en la medida en que sepa ser cauce e intérprete fiel de la necesidad de comunicación -a múltiples niveles- de la sociedad andaluza.

\section{ANEXO}

Emisoras de Radio en Andalucía (1995)

1) Unión Radio

\begin{tabular}{|c|c|c|c|c|c|c|}
\hline Provincia & SER & DIAL & M-80 & RADIOLÉ & $40 \mathrm{P}$ & SINFO \\
\hline Almería ....................... & 2 & 1 & 1 & 1 & 1 & - \\
\hline Cádiz ................................ & 6 & 2 & 1 & 3 & 3 & 1 \\
\hline 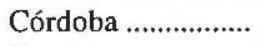 & 4 & 2 & - & 1 & 1 & - \\
\hline Granada ...................... & 5 & 1 & 1 & 1 & 1 & 1 \\
\hline Huelva .......................... & 3 & 1 & - & - & 1 & - \\
\hline Jaén .......................... & 6 & 4 & 1 & 1 & 2 & - \\
\hline Málaga ........................ & 3 & 3 & 1 & 1 & 1 & 1 \\
\hline 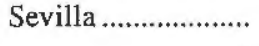 & 3 & 4 & 1 & 2 & 1 & 1 \\
\hline Andalucía .................... & 32 & 18 & 6 & 11 & 11 & 4 \\
\hline
\end{tabular}

2) Onda Cero

\begin{tabular}{|c|c|c|c|}
\hline Provincia & Onda Cero & Onda 10 (Música) & Otras \\
\hline Almería .................................. & 3 & 2 & - \\
\hline 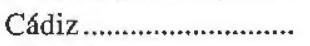 & 4 & 2 & - \\
\hline Córdoba & 5 & 2 & - \\
\hline 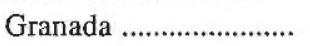 & 4 & 3 & - \\
\hline 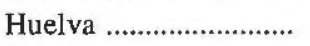 & 2 & 1 & - \\
\hline 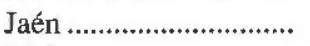 & 3 & 1 & - \\
\hline 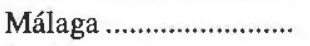 & 3 & 3 & 1 \\
\hline Sevilla ................................ & 4 & 2 & - \\
\hline Andalucía .......................... & 28 & 16 & 1 \\
\hline
\end{tabular}




\section{3) $\mathrm{COPE}$}

\section{Provincia}

COPE

Cadena 100

Almería

2

Cádiz...

4

Córdoba

1

Granada

3

Huelva

1

Jaén

2

Málaga

1

Sevilla

2

Andalucía

16

8

\section{4) Cadena Ibérica}

\begin{tabular}{|c|c|c|}
\hline Provincia & $\mathrm{CI}$ & Top 40 \\
\hline 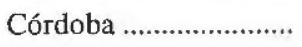 & 1 & \\
\hline Sevilla ........................... & 1 & 2 \\
\hline Andalucía ..................... & 2 & 2 \\
\hline
\end{tabular}

\section{5) Radio Pública}

\begin{tabular}{|c|c|c|c|}
\hline Provincia & $\operatorname{RNE}(*)$ & CANAL SUR(*) & MUNICIPALE \\
\hline Almería ........................... & 1 & 1 & 19 \\
\hline 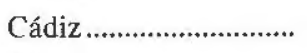 & 2 & 3 & 22 \\
\hline 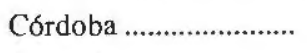 & 1 & 1 & 18 \\
\hline Granada ........................... & 1 & 1 & 22 \\
\hline 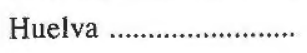 & 1 & 1 & 17 \\
\hline 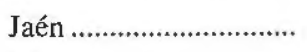 & 1 & 1 & 9 \\
\hline Málaga ............................. & 2 & 1 & 16 \\
\hline 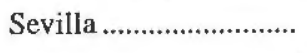 & 1 & 1 & 28 \\
\hline Andalucía .................... & 10 & 10 & 151 \\
\hline
\end{tabular}

(*) Cada emisora de RNE ofrece normalmente 4 canales (RN-1, RN-2, RN-3 -Música clásica- y RN-5) y dos cada emisc de Canal Sur Radio. 


\section{6) Independientes e Ilegales}

\begin{tabular}{lcc}
\hline Provincia & Independientes & Ilegales \\
\hline Almería ................. & - & 22 \\
Cádiz ................... & 1 & 30 \\
Córdoba ................ & 1 & 4 \\
Granada .................. & 1 & 11 \\
Huelva .................... & 1 & 19 \\
Jaén ........................ & 2 & 10 \\
Málaga ..................... & 1 & 25 \\
Sevilla ....................... & 3 & 31 \\
\hline
\end{tabular}

\section{Resumen por Empresas (canales)}

Unión Radio

COPE

Onda Cero

RNE 40

CSR 20

Cadena Ibérica 4

Radio Ecca 1

Municipales 151

Independientes 10

Ilegales 152

Andalucía 529

Fuente: Elaboración propia a partir de datos procedentes de Junta de Andalucía (Dirección Gral. de Comunicación Social), Anuario de la Música 1996 (incluye relación de emisoras de cadenas musicales) y las propias cadenas. 


\section{FUENTES Y BIBLIOGRAFÍA}

CEBRIÁN HERREROS, MARIANO, “Información radiofónica. Mediación técnica, tratamien. to y programación", Editorial Síntesis, Madrid, 1994.

MARTÍ MARTÍ, JOSÉ M. (y otros), "La radio local en España. Tendencias". Universidac Menéndez Pelayo, Cuenca, 1994 (ejemplar mecanografiado).

MERAYO PÉREZ, ARTURO, "Para entender la radio. Estructura del proceso informativc radiofónico", Universidad Pontificia, Salamanca, 1992.

VV. AA., "Comunicación social 1995. Tendencias", Madrid, Fundesco, 1995.

VV. AA., "Jornadas de las Administraciones públicas sobre Radio", Generalitat, Valencia, 1995

VV. AA., "La Radio del futuro", C M Guadaira, Sevilla, 1995 (folleto).

\section{Revistas:}

"Voces y culturas", n² 2/3. Barcelona, 1991. (Monográfico: "Modelos de radio. Transformaciór y continuidad").

\section{Programas radiofónicos:}

"La Radio de Julia", Onda Cero, monográfico del 4 de octubre de 1995 dedicado a la crisis de la Radio. 